\title{
Estimation of Rotor Flux using Neural Network Observer in Speed Sensorless Induction Motor Drive
}

\author{
C. Kamal Basha \\ EEE Department \\ Madanapallelnst. of Technology \& Science \\ Madanapalle, Chittoor(Dist.), A.P,India
}

\author{
M. Suryakalavathi \\ EE Department \\ JNTUH College of Engineering \\ Kukatpalle, Hyderabad, A.P,India
}

\begin{abstract}
In speed sensorless controlled induction motor drive, the rotor flux based Model Reference Adaptive System (MRAS) for is more popular. In MRAS, the voltage model equations are used in the reference model, which leads to poor performance of the drive at low speeds. In this paper, a new stator current based MRAS is presented. In this measured stator currents of induction motor are used as a reference model to avoid the use of a pure integrator. Estimated stator currents are used as an adjustable model. The estimation of stator currents requires the information of the rotor flux which can be obtained from the voltage or current model. This encounters instability and dc drift. To overcome these problems, flux observer is proposed based on Neural Network (NN). This offline trained multilayer feed-forward $\mathrm{NN}$ flux observer applied to indirect vector controlled speed sensorless induction motor drive has been verified by MATLAB/SIMULINK.
\end{abstract}

\section{General Terms}

Neural Networks, Power Electronics and Drives et. al.

\section{Keywords}

Induction Motor, Sensorless control, Model Reference Adaptive System (MRAS), Neural Network flux observer, Vector control.

\section{INTRODUCTION}

The speed of an induction motor is usually measured by using a speed sensor. But the speed sensors are not suitable under varying environmental conditions, as the measurement suffers due to large mechanical shocks. It also reduces the reliability and increases the cost of the drive. Various control algorithms for the estimation of the speed have already been proposed. In $[1,2]$ the voltage and current models of the induction motor (IM) have been used together for flux estimation. By using estimated flux information the speed of the induction motor was calculated. The full order observers in [3] - [10] estimate all the state variables and are sensitive to noise.

MRAS is a special kind of observer. If rotor speed (as an extended state) is included in the dynamic model of an induction motor, the MRAS observer can be used to relinearize the nonlinear state model for each new estimate as it becomes available. The MRAS is based on the principle, in which the outputs of two models - one independent of the rotor speed (reference model) and the other dependent on the rotor speed(adjustable model) are used to form an error vector[11]-[14]. The error vector is driven to zero by an adaptation mechanism which yields the estimated rotor speed. Depending on the choice of output quantities that form the error vector, several MRAS structures are possible. The major three groups of MRAS based speed estimators developed so for are given below.
The rotor flux error based MRAS scheme developed by Tami[13] is one of the most popular method. The flux error is calculated using voltage and current models of the rotor flux. The speed is determined through the closed loop signal from the output of the proportional-integral(PI) controller operated by the flux error signal.

In the back electromotive force (back EMF) error based MRAS scheme[14], the error vector used for the rotor speed correction is obtained from the comparison of the measured and calculated back EMF of the induction motor.

In the stator current error based MRAS scheme[15-16], the stator current is estimated by suitable stator current model and compared with measured value is used to obtain the speed error correction signal

In [25] a new stator current based MRAS was proposed in which the reference model comprises the measured stator current components. This makes the reference model free from pure integration problems and insensitive to motor parameter variations. Stator voltage-current model used for the estimation of stator currents used as an adjustable model. This stator current model needs the information of the rotor flux. This rotor flux can be obtained from the voltage or current model, the use of such a model gives poor performance at the low speeds as well as instability in the regenerating mode of operation.

Neural Network based estimators are best alternate solution for the flux estimation [17-20]. Estimation of flux from the measured stator currents and voltages has been discussed in [21-22]. Mapping capability of the neural network with the nonlinear dynamic system was well demonstrated in the literature [23]. NN trained using input/output data for flux estimation was proposed in [24].

In this paper the application of $\mathrm{NN}$ flux observer for the estimation of rotor flux in adjustable model of the new stator current based MRAS scheme used for the speed estimation is presented. Performance of the proposed observer is verified through MATLAB simulation.

\section{INDUCTION MOTOR MODEL}

The induction motor can be represented by its dynamical model expressed in the stationary frame in terms of the stator current and rotor flux as follows.

$$
\frac{d i_{s}^{s}}{d t}=\frac{1}{\sigma L_{s}}\left(u_{s}^{s}-R_{s} i_{s}-\frac{L_{m}}{L_{r}} \frac{d \lambda_{r}^{s}}{d t}\right)
$$


$\frac{d \lambda_{r}^{s}}{d t}=\frac{L_{m}}{T_{r}} i_{s}^{s}-\left(\frac{1}{T_{r}}-J \omega_{r}\right) \lambda_{r}^{s}$

The dynamic model can be described by the following state equation.

$$
\frac{d}{d t}\left[\begin{array}{c}
i_{s}^{s} \\
\lambda_{r}^{s}
\end{array}\right]=\left[\begin{array}{ll}
a_{11} & a_{12} \\
a_{21} & a_{22}
\end{array}\right]\left[\begin{array}{c}
i_{s}^{s} \\
\lambda_{r}^{s}
\end{array}\right]+\left[\begin{array}{c}
b_{1} \\
0
\end{array}\right] u_{s}^{s}
$$

The electromagnetic torque developed by the motor is expressed in terms of rotor flux and stator currents as

$T_{e}=P * \lambda_{r}^{s} \otimes i_{s}^{s}$

Where the load torque acts as a disturbance via the mechanical relation

$\frac{d \omega}{d t}=\frac{N_{p}}{J}\left(T_{e}-T_{L}\right)$

Where $R_{s}$ is stator resistance, $L_{r}$ is rotor inductance, $L_{m}$ is mutual inductance, $u_{\mathrm{s}}$ stator voltage, $\mathrm{i}_{\mathrm{s}}$ stator current, $\lambda_{\mathrm{r}}$ rotor flux, $\mathrm{N}_{\mathrm{p}}$ number of pair of poles, $\mathrm{J}$ moment of inertia, $\mathrm{T}_{\mathrm{r}}$ rotor time constant and $\mathrm{T}_{\mathrm{e}}$ electromagnetic torque.

\section{MODEL REFERENCE ADAPTIVE SYSTEM}

The model reference adaptive system (MRAS) approach uses two models. The model that does not involve the quantity to be estimated is considered as a reference model. The model that has the quantity to be estimated involved is considered as the adaptive model. The output of the adaptive model is compared with that of the reference model, and the difference is used to estimate the speed.

\subsection{Mathematical model of the stator current based MRAS speed estimator}

The proposed MRAS adaption algorithm is based on the comparison of measured and estimated stator current of the induction motor. This comparison is used to obtain the rotor speed. In the classical MRAS, error between the two rotor flux vectors is estimated by the two rotor flux models. The mathematical model of the proposed algorithm is described by the following equations.

$$
\begin{aligned}
& \frac{d \hat{\lambda}_{d r}^{s}}{d t}=-\frac{1}{T_{r}} \hat{\lambda}_{d r}^{s}-\hat{\omega}_{r} \hat{\lambda}_{q r}^{s}+\frac{L_{m}}{T_{r}} i_{d s}^{s} \\
& \frac{d \hat{\lambda}_{q r}^{s}}{d t}=-\frac{1}{T_{r}} \hat{\lambda}_{q r}^{s}-\hat{\omega}_{r} \hat{\lambda}_{d r}^{s}+\frac{L_{m}}{T_{r}} i_{q s}^{s} \\
& \frac{d \hat{i}_{d s}^{s}}{d t}=\frac{\beta}{T_{r}} \hat{\lambda}_{d r}^{s}+\beta \hat{\omega}_{r} \hat{\lambda}_{q r}^{s}-K_{1} \hat{i}_{d s}^{s}+K_{2} u_{d s}
\end{aligned}
$$

$$
\frac{d \hat{i}_{q s}^{s}}{d t}=\frac{\beta}{T_{r}} \hat{\lambda}_{q r}^{s}-\beta \hat{\omega}_{r} \hat{\lambda}_{d r}^{s}-K_{1} \hat{i}_{q s}^{s}+K_{2} u_{q s}
$$

$$
\text { Let } \bar{i}_{d s}^{s}=\hat{i}_{d s}^{s}-i_{d s}^{s}, \bar{i}_{q s}^{s}=\hat{i}_{q s}^{s}-i_{q s}^{s}
$$

The estimated rotor speed $\hat{\omega}_{r}$ by the adaptation algorithm is given by

$$
\hat{\omega}_{r}=K_{p}\left(\bar{i}_{q s}^{s} \hat{\lambda}_{d r}^{s}-\bar{i}_{d s}^{s} \hat{\lambda}_{q r}^{s}\right)+K_{I} \int\left(\bar{i}_{q s}^{s} \hat{\lambda}_{d r}^{s}-\bar{i}_{d s}^{s} \hat{\lambda}_{q r}^{s}\right) d t
$$

From the above equations, rotor flux model and stator current model are adjusted by the estimated speed according to the schematic diagram shown in Figure. 1.

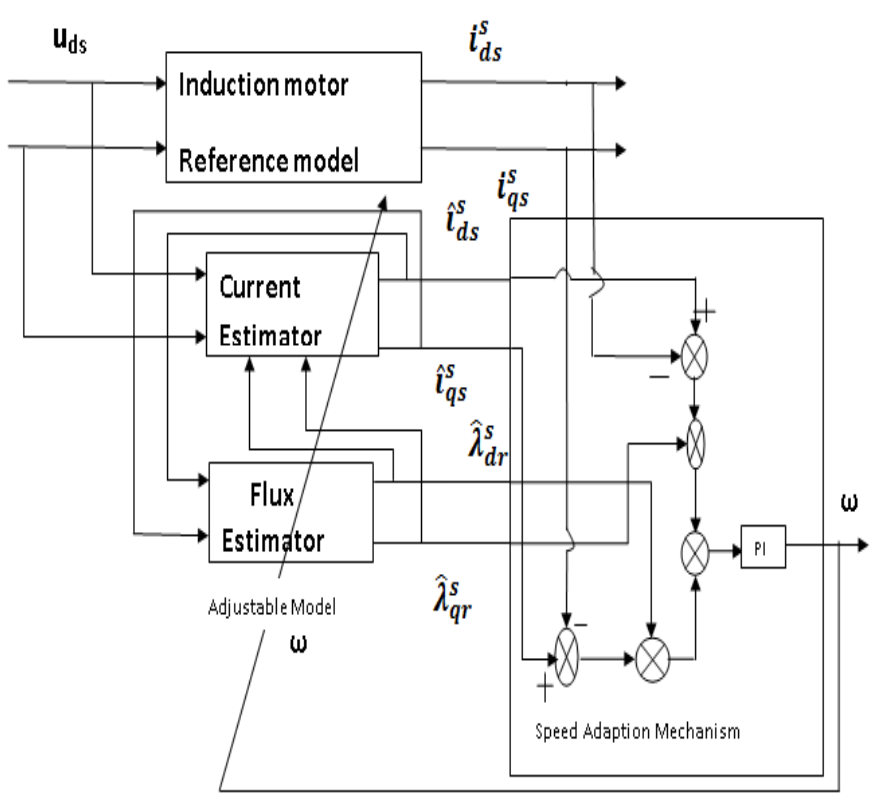

Figure: 1 Stator current based MRAS rotor speed estimator.

\section{NN ROTOR FLUX ESTIMATION}

In particular cases the use of current model for the estimation of the rotor flux causes instability at the regenerating mode of operation. To overcome this problem an offline trained 8-20-2 multilayer feed forward $\mathrm{NN}$ for the estimation of rotor flux in adjustable model of stator current based MRAS is proposed. The inputs to the $\mathrm{NN}$ are the present and past values of the d-q components of voltage and currents. The structure of the neural network is shown in Figure. 2. The number of neurons in the hidden layer is chosen by trail and error technique. The output layer consists of two neurons representing d-q axis rotor flux components in stationary reference frame. Due to approximation of the nonlinear function, the tansigmoid activation function is used in both hidden and output layers.

To obtain the training data for NN, the IM is simulated in different operating conditions in the low speed region (100 rpm to $-100 \mathrm{rpm}$ ) at various load levels. The present and past samples of the d-q components of the reference stator voltages and output stator currents : $\mathrm{u}_{\mathrm{sd}}(\mathrm{k}), \mathrm{u}_{\mathrm{sd}}(\mathrm{k}-1), \mathrm{u}_{\mathrm{sq}}(\mathrm{k}), \mathrm{u}_{\mathrm{sq}}(\mathrm{k})$, $\mathrm{u}_{\mathrm{sq}}(\mathrm{k}-1), \mathrm{i}_{\mathrm{sd}}(\mathrm{k}), \mathrm{i}_{\mathrm{sd}}(\mathrm{k}-1), \mathrm{i}_{\mathrm{sq}}(\mathrm{k}), \mathrm{i}_{\mathrm{sq}}(\mathrm{k})$ and $\mathrm{i}_{\mathrm{sq}}(\mathrm{k}-1)$ are used as a inputs. $\psi_{r d}(k), \psi_{r q}(k)$ are outputs from the rotor flux current model 5000 input/output patterns are used to train the NN. 
The training is performed off-line using the LevenbergMarquardt algorithm. After the training the Mean Squared Error (MSE) between targets and neural network outputs decays to 0.003 after 1500 epochs. The new stator current based MRAS speed estimator with NN rotor flux observer in adjustable model is shown in Figure. 3.

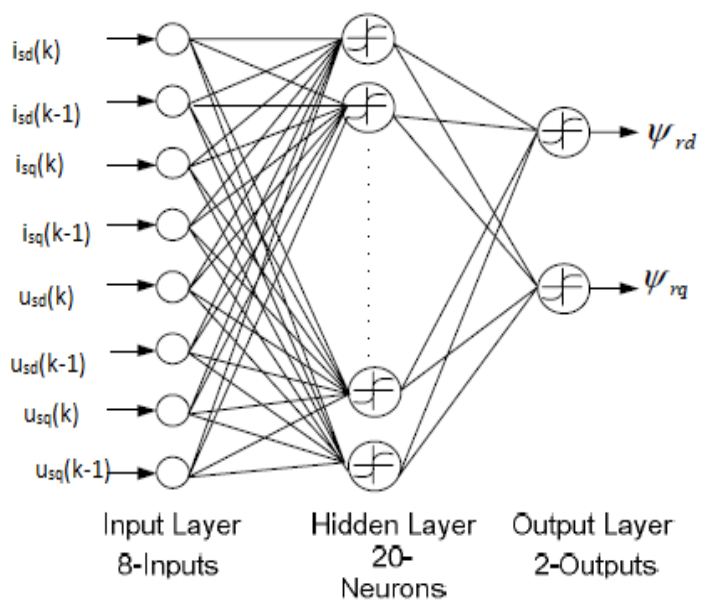

Figure: 2 Structure of the Neural Network flux observer.

\section{RESULTS AND DISCUSSION}

The dynamic behavior of the drive with Neural network flux observer in stator current based MRAS estimator for indirect field oriented control drive was investigated by using computer simulation with Matlab/Simulink. Figure. 4 shows the performance of the drive at the stating in terms speed, torque and stator currents.

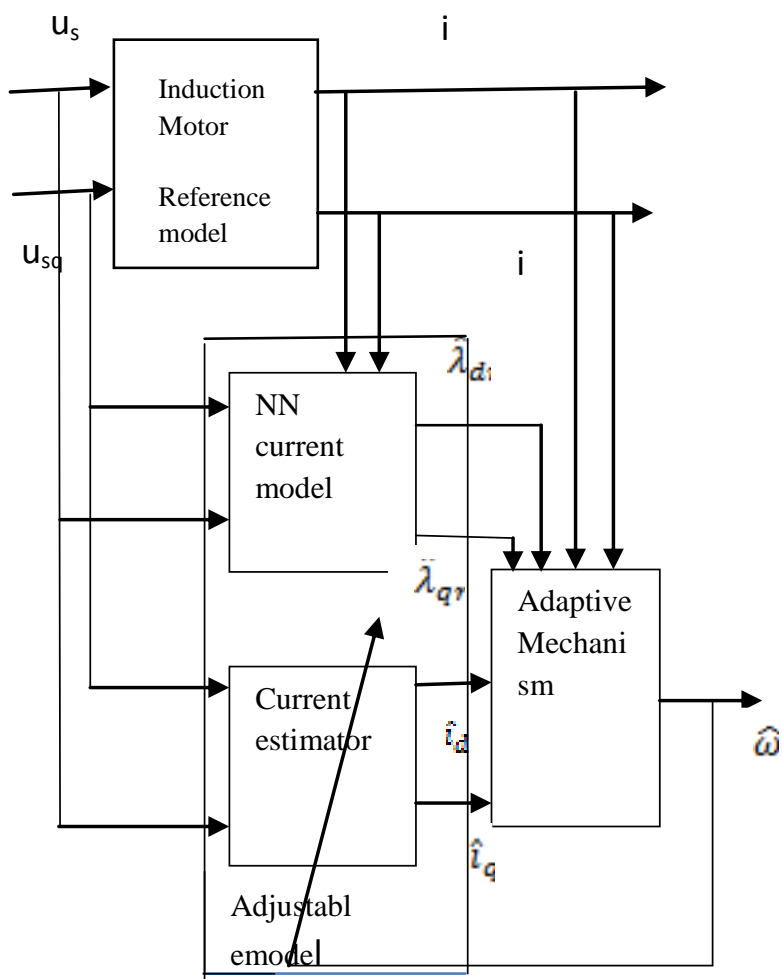

Figure: 3The new stator current based MRAS speed estimator with $\mathrm{NN}$ rotor flux observer in adjustable model.
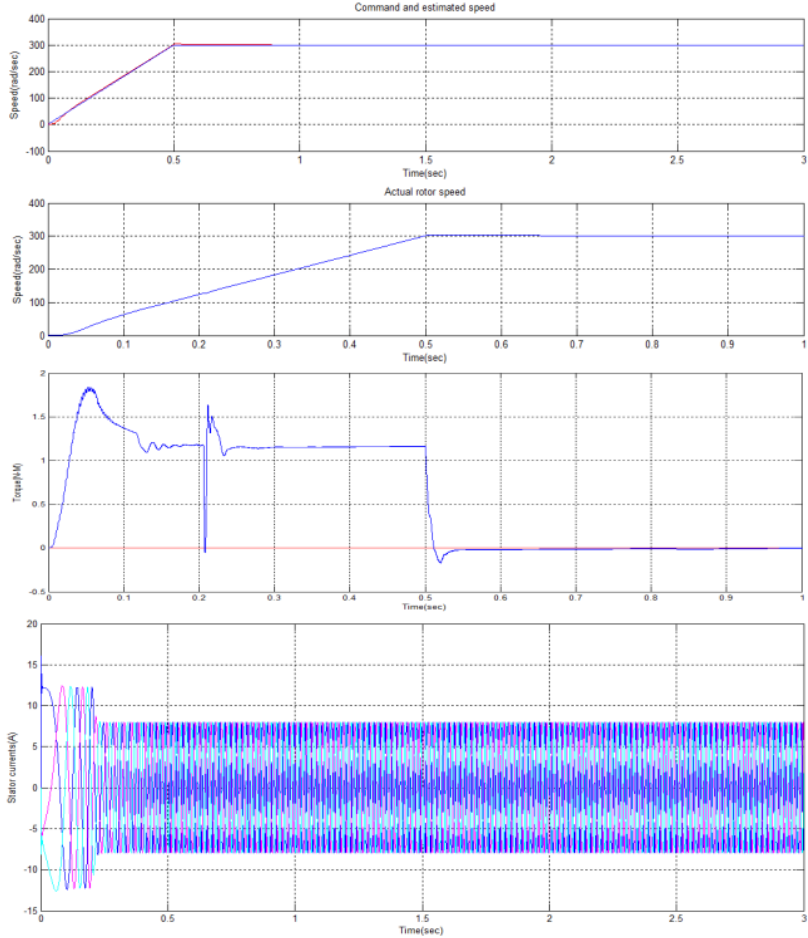

Figure: 4. Transients at the starting for the speed of $300 \mathrm{rad} / \mathrm{sec}$. 

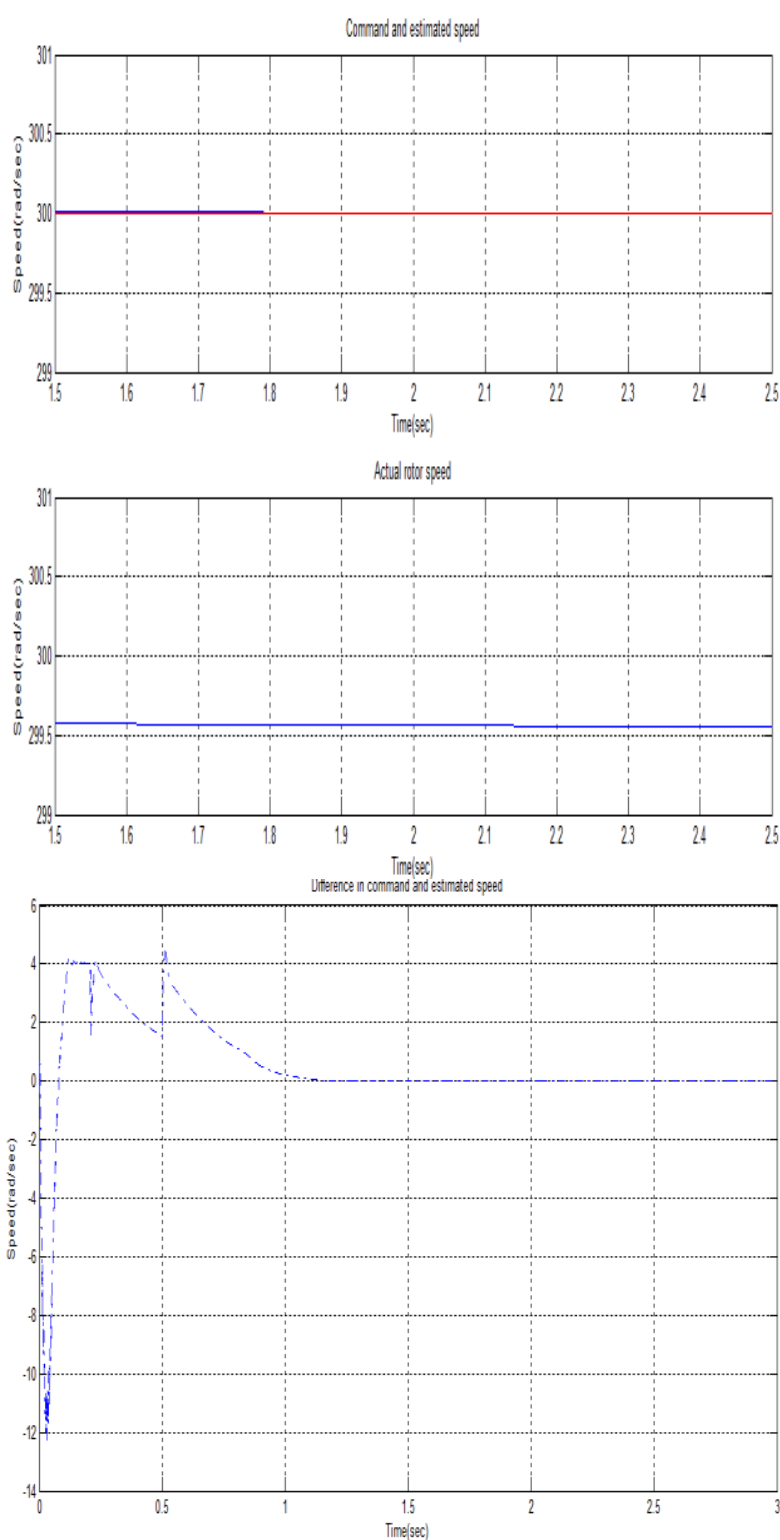

Figure: 5. Estimated and actual rotor speed transients at the steady state the speed of $300 \mathrm{rad} / \mathrm{sec}$.

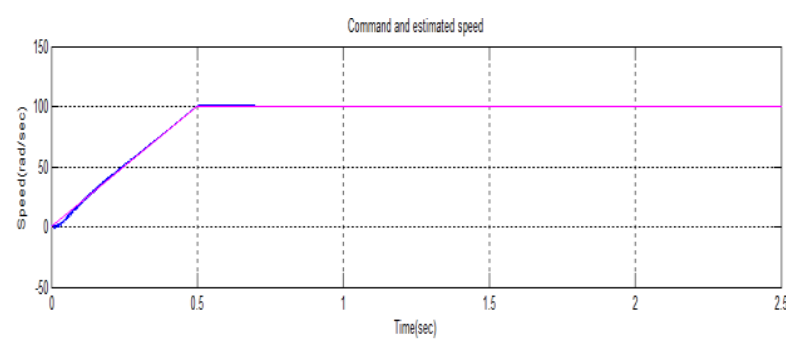

Actud rotor spees

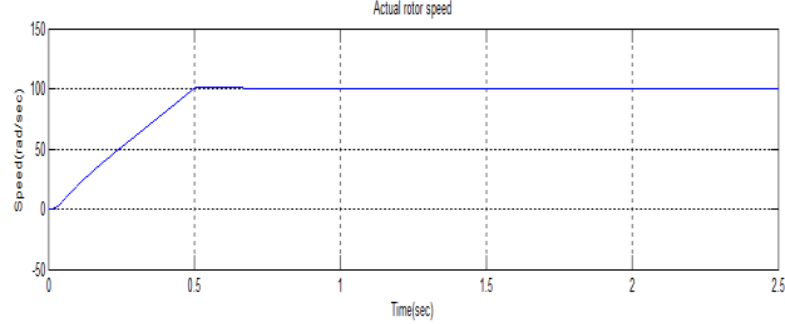

(a)

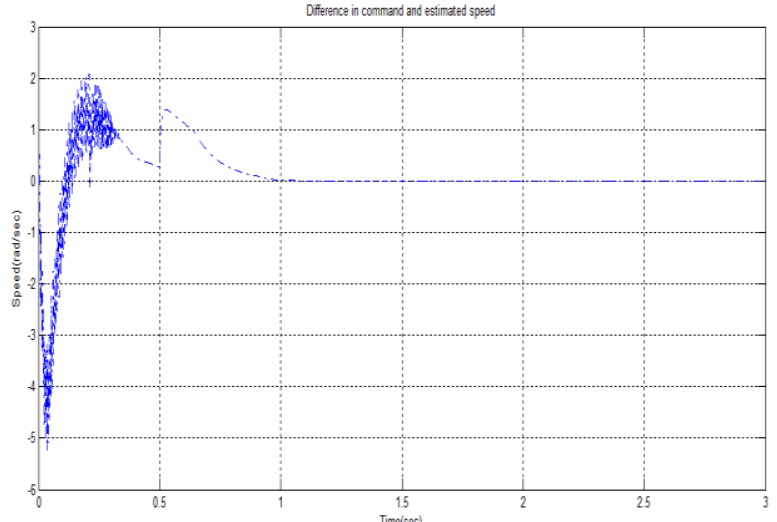

(b)

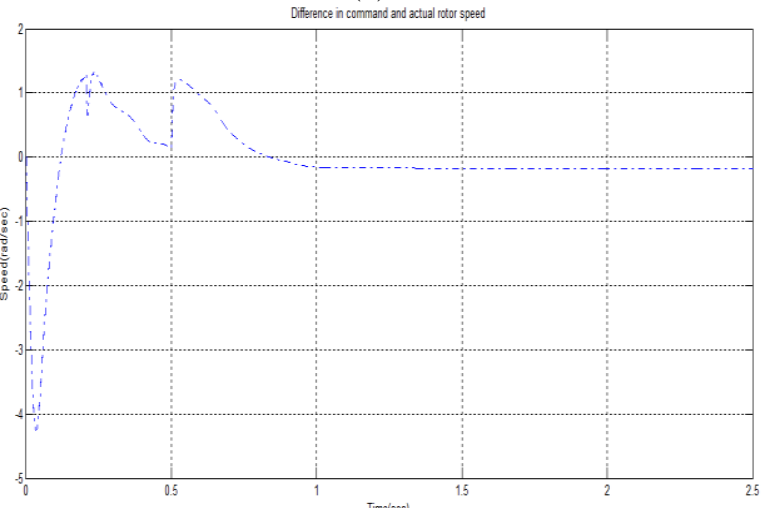

(c)

Figure: 6. (a) Estimated and actual rotor speed at 100 $\mathrm{rad} / \mathrm{sec}$. (b) Error in speed between command and estimated. (c) Error in speed between command and actual rotor speed.
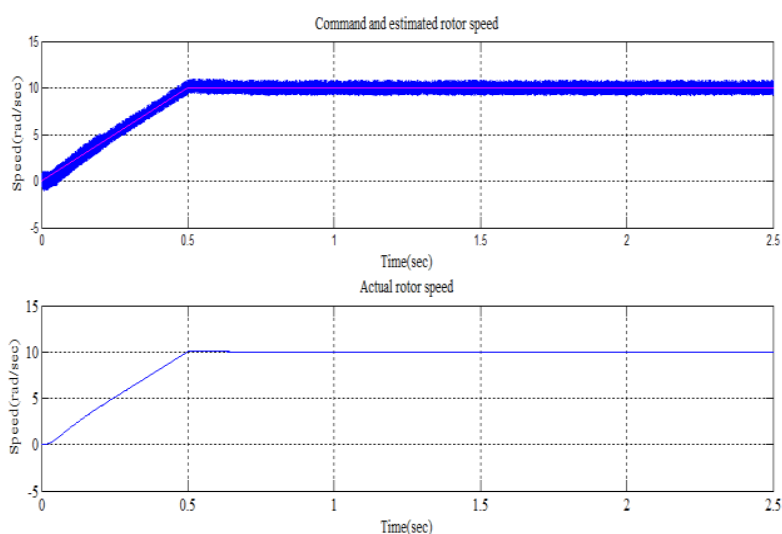

(a)

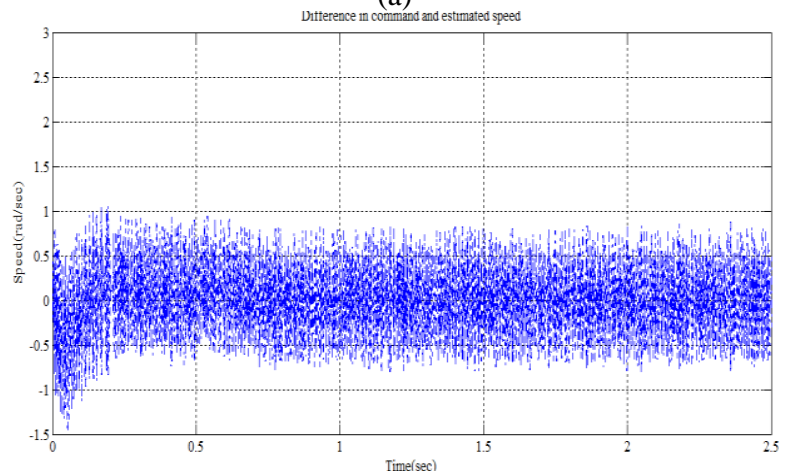

(b) 


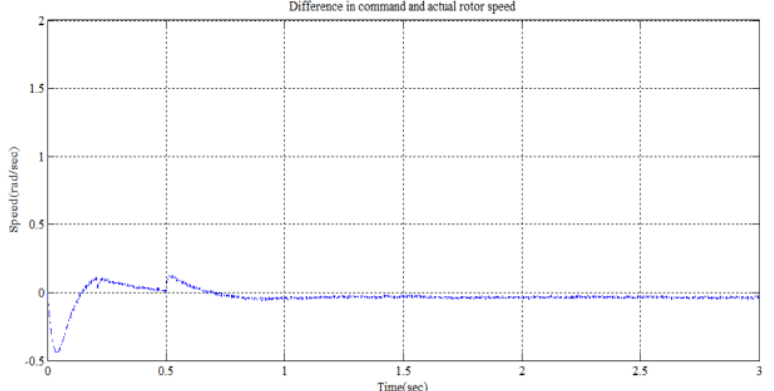

(c)

Figure: 7. (a) Estimated and actual rotor speed at 10 rad/sec. (b) Error in speed between command and estimated. (c) Error in speed between command and actual rotor speed.

Figure. 5, 6 and 7 show the estimated and actual rotor speed at the steady state for the speed of $300 \mathrm{rad} / \mathrm{sec}, 100 \mathrm{rad} / \mathrm{sec}, 10$ $\mathrm{rad} / \mathrm{sec}$. respectively. It shows that error in speed both in estimated and actual speed is less than $5 \mathrm{rad} / \mathrm{sec}$.
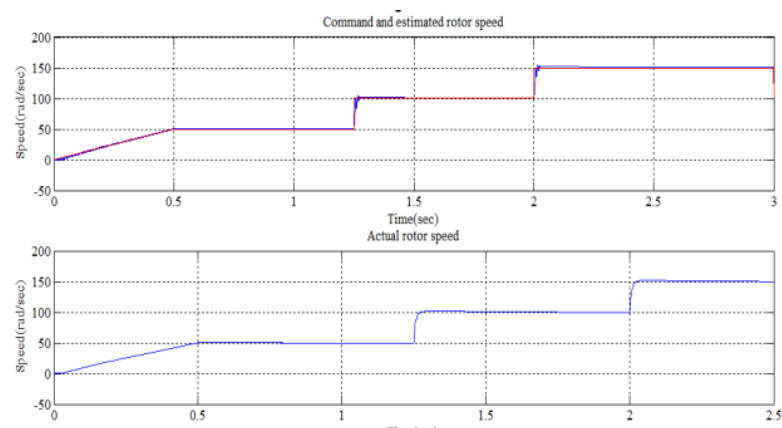

(a)

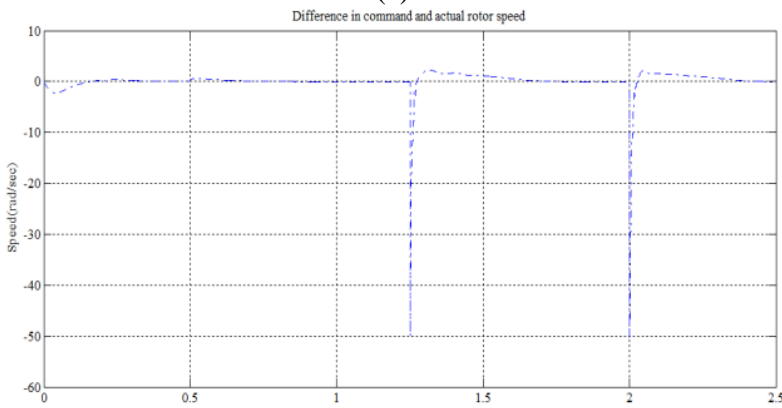

(b)

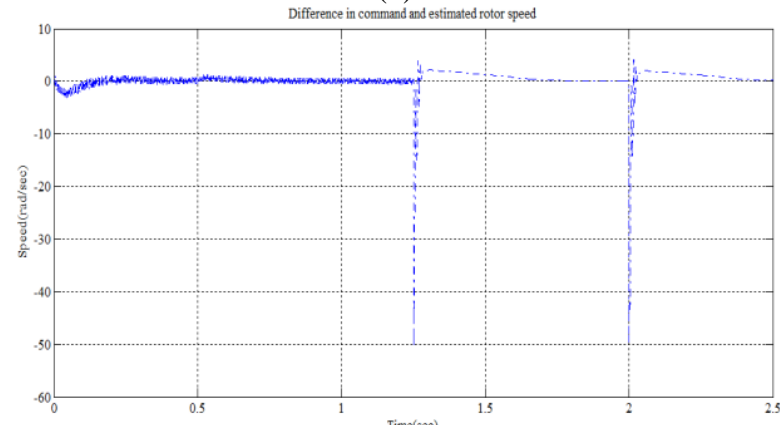

(c)

Figure: 8. (a) Estimated and actual rotor speed for step change in speed. (b) Error in speed between command and estimated. (c) Error in speed between command and actual rotor speed.
In Figure. 8. A step command of 50rad/sec is applied at 1.25 sec and $2 \mathrm{sec}$.
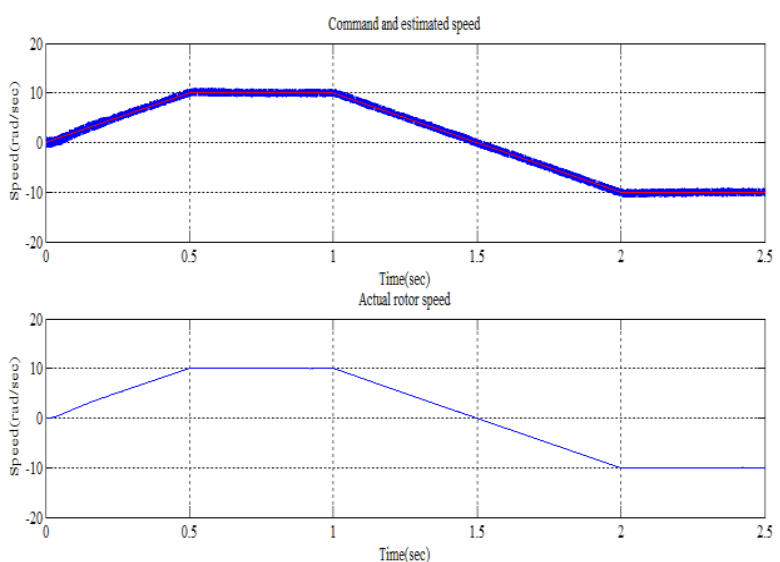

(a)

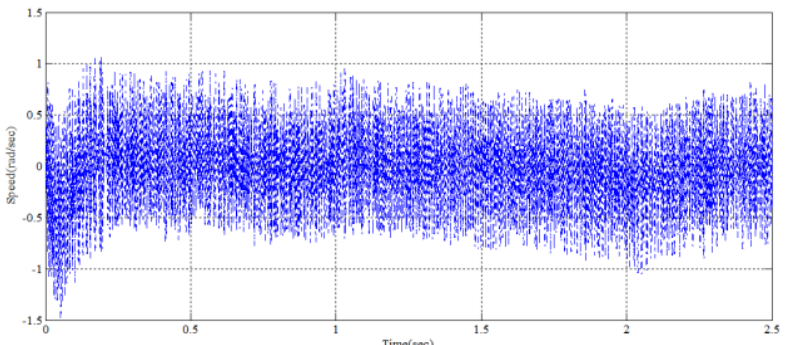

(b)

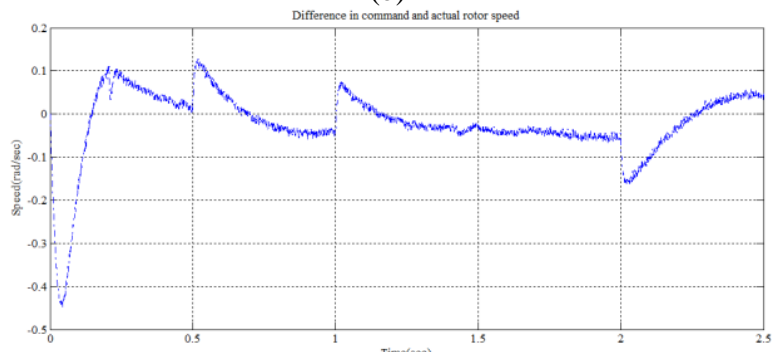

(c)

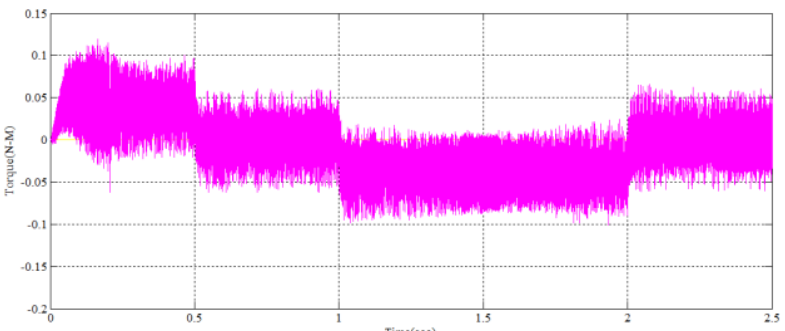

(d)

Figure: 9. (a) Estimated and actual rotor speed for speed reversal at $t=1$ sec. (b) Error in speed between command and estimated. (c) Error in speed between command and actual rotor speed. (d) Variation in torque.

In Fig. 9 a speed is changed from $+10 \mathrm{rad} / \mathrm{sec}$ to $-10 \mathrm{rad} / \mathrm{sec}$. From the Fig. 8 and 9 it is evident that, the drive with step changes in speed and speed reversal at lo speeds shows the good performance by the application of the NN flux observer.

\section{CONCLUSION}

A speed sensorless indirect field oriented controlled induction motor drive based on proposed MRAS with NN flux observer in adjustable model was analyzed. By using the proposed neural network flux observer in stator current based MRAS, 
oscillations and speed error at the low speed are reduced and also it gives stable operation in regenerating mode. From the numerical simulations, it was observed that the performance of the proposed MRAS for IFOC drive has been improved.

\section{REFERENCES}

[1] Rajasekara.K, Kawamura.A, K.Matsuse, "Sensorless Control of AC MotorDrives: Speed and Position Sensorless Operation", IEEE Press, Piscataway, NJ, 1996.

[2] L. Ben Brahim, S. Tadakuma, and A. Akdag, "Speed control of induction motor without rotational transducers," IEEE Trans. Ind. Appl., vol. 35, no. 4, pp. 844-850, Jul./Aug. 1999.

[3] Hisao Kubota, KoukiMastuse and Takayoshi Nakano, "DSP based speed adaptive flux observer of induction motor", IEEE Trans. on Industry Applications, Vol.29,No.2, 1993, pp344-348.

[4] Abbou, A.; Mahmoudi, H. "Implementation of a Sensorless Speed Control of Induction Motor Using RFOC Strategy" International Review of Electrical Engineering(IREE), pp-730-737, JUL-AUG 2008.

[5] E.Levi and M.ang, "A speed estimator for high performance sensorless control of induction motor in the field weakening region" IEEE Trans.Power Electronics, vol.17,no.3,pp.365-378, May 2002.

[6] Y.R.Kim,K.S.Sul and M.H.Park, "Speedsensorless vector control of induction motor using extended Kalman filter" IEEE Trans. Ind. Appl., vol.30, no.5,pp12251233,Sep/Oct.1994.

[7] Zhang Wei, Cai Wei Sheng "Flux Observer for Field Oriented Induction Motors based on EKF" 2010 2nd International Conference on Software Technology and Engineering(ICSTE) pp v2-240-v2-243.

[8] M.BenHamed and L.Sbita, "Speed Sensorless Indirect Stator Field Oriented Control of Induction Motor based on Luenberger observer", IEEE-ISIE06-2006.

[9] Mezouar, A.; Fellah, M. K.; Hadjeri, S. "Speed sensorless vector control of induction motors using singularly perturbed sliding mode observer" International Review of Electrical Engineering(IREE), pp398 -405, MAY-JUN 2007.

[10]. K. Gherram, K.Yazid and M. Menaa "Sensorless Indirect Vector Control of an Induction Motor by ANNs Observer and EKF" 18th Mediterranean Conference on Control \& Automation Congress Palace Hotel, Marrakech, Morocco June 23-25, 2010, pp 521-526.

[11] M. M. Krishan, "Sliding Mode Control with MRAC Technique Applied to an Induction Motor Drives" International Review of Automatic Control (IREACO) Vol. 1. n. 1, pp. 42-48, May 2008.

[12] $\mathrm{Hu}$ Jun B.R.uggal and M.V.ilathgamuwa, "A MRAS based speed sensorless field oriented control of induction motor with on line stator resistance tuning" IEEE Trans.Ind.Appl.1998.

[13] S.Tami, H.Sugimoto and Y.Masao "Speed sensorless vector control of induction motor with model reference adaptive system" in conf.IEEE/IAS. Annu.Meeting, 1987,pp.189-195.

[14] M.Rashed and A.F.Stronach, "A stable back-EMF MRAS based sensorless low speed inaction motor drive insensitive to stator resistance variation," Proc.Inst.Elect.Eng Elect. Power Appl., vol.151,no6, pp 1685-693, nov.2004.

[15] T.Orlowska-Kowaska and M.ybkowski, “ Novel MRAS type rotor speed and flux estimator for speed sensorless induction motor drive,"Elct.Rev.(polond), vol.82, no.11, pp35-38,2006.

[16] M. Mostefai, A. Bendiabdellah "A MRAS-based Speed Sensorless Vector Control of Induction Motor with Rotor-Inverse Time Constant Adaptation" International Review of Automatic Control (IREACO), Vol. 1, pp. 4956, May 2008

[17] S. K. Mondal, J. O. P. Pinto, and B. K. Bose, "A neural network based space-vector PWM controller for a three voltage-fed inverter induction motor drive," IEEE Trans. Ind. Appl., vol. 38, no. 3, pp. 660-669, May 2002.

[18] B. Burton, R. G. Harley, G. Diana, and J. L. Rodgerson, "Implementation of a neural network to adaptively identify and control VSI-fed induction motor stator currents," IEEE Trans. Ind. Appl., vol. 34, no. 3, pp. 580-588, May-Jun. 1998.

[19] L. Ben-Brahim, S. Tadakuma, and A. Akdag, "Speed control of induction motor without rotational transducers," IEEE Trans. Ind. Appl., vol. 35, no. 4, pp. 844-850, Jul./Aug. 1999.

[20].B. Karanayil, M. F. Rahman, and C. Grantham, "Online Stator and rotor resistance estimation scheme using artificial neural networks for vector controlled speed sensorless induction motor drives," IEEE Transactions on Industrial Electronics, vol. 54, pp. 167-176, 2007.

[21] L. M. Grzesiak and B. Ufnalski, "Neural stator flux estimator with dynamical signal preprocessing," in Proc. IEEE AFRICON, 2004.

[22] A. Ba-Razzouk, A. Cheriti, G. Olivier, and P. Sicard, "Field oriented control of Induction Motors using Neural Network decouplers," IEEE Transactions on Power Electronics, vol. 12, pp. 752-763, 1997.

[23] K.S.Narendra and Parthasarathy, K. "Identification and control of dynamical systems using neural networks". In IEEE Trans. Neural Network., vol. 1, no. 1, pp. 4-27. 1990.

[24] Shady M. Gadoue, Member, IEEE, Damian Giaouris, Member, IEEE, and John W. Finch, Senior Member, IEEE"Sensorless Control of Induction Motor Drives at Very Low and Zero Speeds Using Neural Network Flux Observers" IEEE Transactions on Industrial Electronics vol. 56, no. 8, , pp,3029-3039 August 2009

[25] C.KamalBasha and M.Suryakalavathi "Speed sensorless vector control of Induction motor using Stator current based MRAS Scheme" International Review of Automatic Control (I.RE.A.CO.), Nov.2011 